\title{
Emerging technologies and their roles during the COVID-19 pandemic and safety challenges of frontline medical staff: a rapid review
}

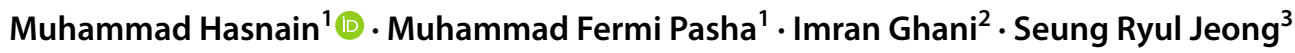

Received: 15 June 2020 / Accepted: 25 July 2021 / Published online: 4 August 2021

(c) Sociedade Brasileira de Engenharia Biomedica 2021

\begin{abstract}
Purpose The coronavirus 2019 (COVID-19) pandemic has rapidly spread worldwide, with an ever-increasing number of confirmed positive cases and mortality rate. Moreover, frontline medical staff fighting with the COVID-19 infection have been infected and show psychological effects of the pandemic. This study presents an overview of the emerging literature on the safety challenges of frontline medical staff and how technology is being used to control the COVID-19 pandemic.

Methods This study conducts a rapid review of available studies by following the "preferred reporting items for systematic reviews and meta-analyses" (PRISMA) guidelines. Sixty-three articles were selected for this rapid review paper from three popular digital data repositories.

Results The majority of the studies chosen focused on the discussion of COVID-19 with regard to China, Singapore, Italy, and the USA. A previously proposed framework is used to synthesize the findings of this study. The results throw light on the several challenges faced by medical staff during the COVID-19 pandemic. Eleven major technologies have been identified in this paper.

Conclusion This work concludes that technology helps in the prevention and detection of the COVID-19 infection, where it specifically helps in reducing the safety challenges of frontline medical staff and monitoring the COVID-19 patients.
\end{abstract}

Keywords Frontline medical staff $\cdot$ Rapid review $\cdot$ Psychological effects $\cdot$ Emerging technology

\section{Introduction}

The first case of a novel coronavirus (COVID-19) was detected in Wuhan, Hubei Province of China. After that, the rapid outbreak of the COVID-19 pandemic occurred in more than 203 locations around the world ( $\mathrm{Li}$ et al. 2020). Previously, it was designated as "severe acute respiratory syndrome coronavirus 2" (SARS-CoV-2). However, the World Health Organization (WHO) termed it as coronavirus 2019 (COVID-19) disease. It is now known that COVID-19

Muhammad Hasnain

muhammad.malik1@monash.edu

Imran Ghani

ghanii@vmi.edu

1 School of IT, Monash University, Ridzuan Condominium, Block C-309, Bandar Sunway, 47500 Petaling Jaya,

Selangor, Malaysia

2 Virginia Military Institute, Lexington, VA, USA

3 Graduate School of Business IT, Kookmin University, Seoul, Korea causes pneumonia, respiratory infections, and even deaths in the population of adults and people with cardiovascular problems, diabetes, hypertension, respiratory disease, and malignancy (Bansal et al. 2020). Palliative care of patients and their families is aimed at avoiding them from the risks of COVID-19 worldwide. However, it has been observed that the current supply of personal protection equipment such as face masks, ventilators, and intensive care units may not be able to meet the projected demands. This nightmare scenario is being experienced throughout the world, including in developed countries such as the USA, UK, France, Italy, and Spain. The number of confirmed COVID-19 infection cases is increasing rapidly. As of May 14, 7,865,794 cases were confirmed worldwide, resulting in 432,394 deaths. China, including the countries mentioned earlier, has borne the brunt of this pandemic. Other than China, the USA, Brazil, Russia, India, the UK, Italy, France, and Spain have also been severely affected by the COVID-19 pandemic.

During the COVID-19 pandemic, the role of Industry 4.0 has been shown for the flexible production line by processing real-time information with the support of artificial 
intelligence (AI) and Internet of things (IoT) technologies. As a result of this, the designing and development processes for the production of medical equipment have been conducted rapidly (Javaid et al. 2020). In addition to AI and IoT, big data and $5 \mathrm{G}$ technologies have also been used to address the COVID-19 risks and develop patients' recovery strategies. To support the decision makers, an AI-based check-up and screening method has also been implemented where possible, which could help physicians to perform earlier diagnosis of COVID-19 infections. East Asian countries such as Japan, Korea, and China have had higher recovery rates than European countries and the USA. The former countries have rapid penetration of the aforementioned technologies (Shaw et al. 2020).

The rapidly increasing COVID-19 pandemic is posing several challenges to different countries in the world. Among these challenges is the safety of the frontline medical staff. The safety of medical staff is paramount; they require strong quality personal protection equipment (PPEs) and disinfection solutions at all times, as they treat the COVID19 patients (Tempe et al. 2020). Even in a recently published research, Ertl-Wagner et al. (2020) emphasized the availability of required PPEs in the radiology departments. Several studies highlight the safety of health workers and argue that medical professionals are at greater risks as they are involved in the noninvasive ventilation of COVID-19 patients (Haghani et al. 2020). Amid these rising challenges of COVID-19, the morale of medical staff is another concern, which should be considered while developing safety strategies against the COVID-19 infection (Tey et al. 2020). Prior to this research work, we have presented combined measures to control the pandemic in Wuhan city, China (Hasnain et al. 2020). There is no discussion on the emerging technologies concerning the COVID-19 pandemic in our previous study. Also, an extensive literature has been published on the research topic for the last several months. To bridge this research gap, we present a rapid review regarding the role of emerging technologies during this pandemic.

We have reviewed many of the published articles on COVID-19, and frontline medical staff alongside emerging technologies, to identify the roles of the technologies in the prevailing situation of the COVID-19 pandemic. This may help research scholars bridge the research gaps and propose extensions in the identified technologies to combat the ongoing outbreak of the COVID-19 pandemic.

\section{Background}

Severe acute respiratory-related coronavirus 2 (SARSCoV-2) was announced as a pandemic on 13 March 2020, leading to unexpected health issues throughout the world. Moreover, this has become a socioeconomic burden. One of the significant issues with the COVID-19 pandemic was the diagnostic testing for timely decision-making (MoralesNarváez and Dincer 2020). Due to the rapidly evolving and novelty of the virus, disseminating accurate and high-quality information has increased in its importance. Librarians in academic health centers or hospitals were suited to face and help in emergent situations, but many of them had faced unfamiliar circumstances regarding COVID-19 disaster preparedness and response (Clifton et al. 2021).

The SARS-CoV-2 pandemic has spread similar to the wildfire. A large part of the world is under lockdown, and we look forward to intelligent and advanced technologies to reduce the adverse impacts of the pandemic. The best industries have become unsuccessful in providing suitable protective measures to their government. Academics believe that emerging technologies can urgently be used globally (Vaishya et al. 2020). Emerging technologies represent valuable tools in managing the different diseases in the current pandemic with limited resources. For instance, cryoablation therapy was suggested for patients who were anxious to delay surgery. Cryoablation therapy as technology has replaced breast cancer surgery during the pandemic (Holmes 2020). This technology has fewer psychosocial, cosmetic, and morbidity impacts.

\section{Research method}

To conduct a rapid review of recently published works, we followed the research method given in the study Simon et al. (2020). The proposed method was primarily based on PRISMA protocol (Moher et al. 2010). PRISMA protocol is based on 27 items. We used significant items of PRISMA protocol, including design, exclusion and inclusion criteria, search strategy, study selection, data extraction, and analysis.

\section{Design}

A timely survey of the chosen papers was performed by following the PRISMA guidelines, as shown in Fig. 1. The checklist and details of PRISMA guidelines are presented for review studies (Liberati et al. 2009). There are 27 items listed in the latter mentioned study. We have followed most of the guidelines to conduct a rapid review of the emerging literature on the emerging technologies and safety challenges of medical staff during the outbreak of the COVID-19 pandemic.

\section{Exclusion criteria}

Based on the proposed research method for this rapid review, we exclude those papers that discuss the safety challenges of the medical staff without discussing the COVID-19 
Fig. 1 PRISMA flowchart diagram

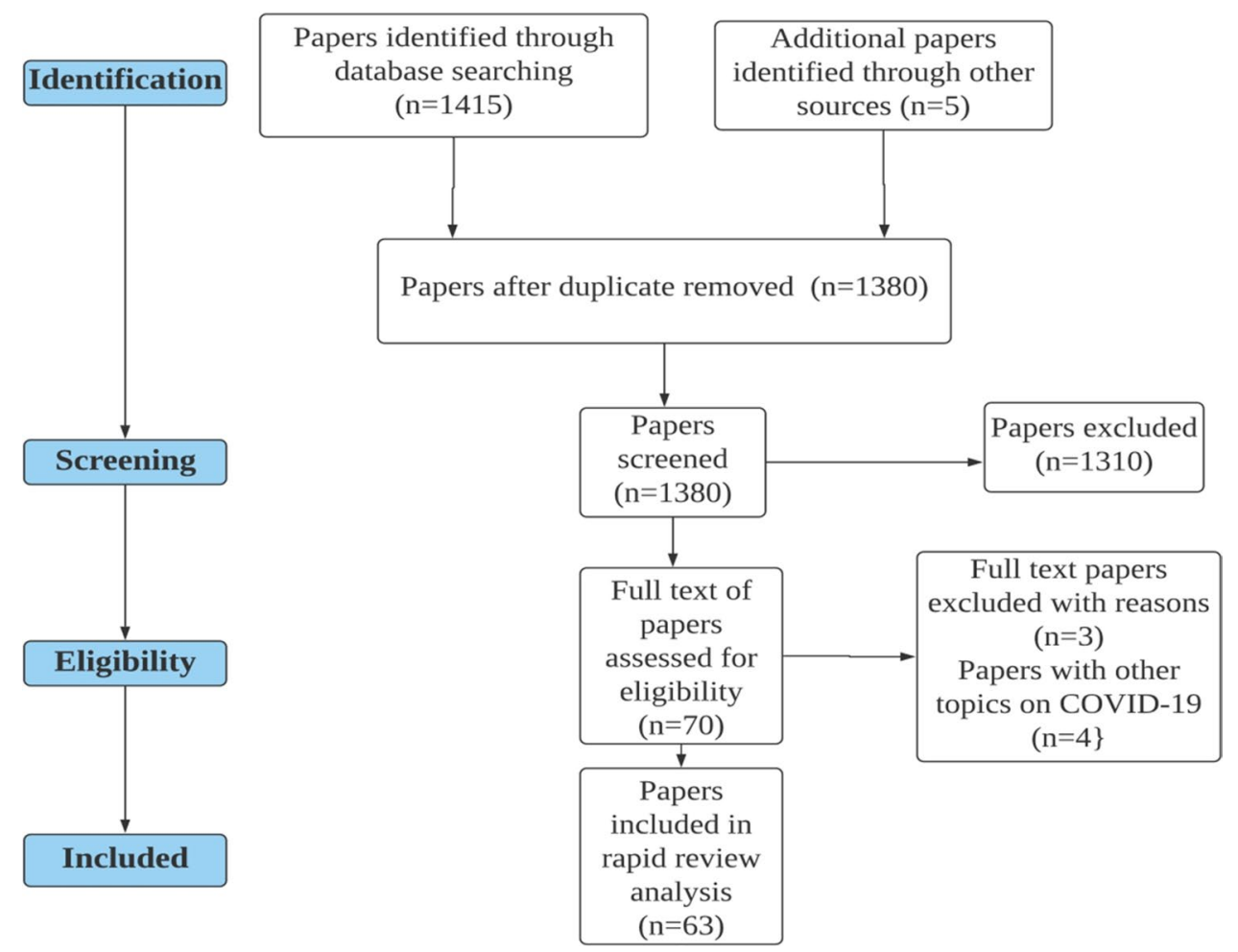

pandemic. Articles written in languages other than English were also excluded. Moreover, we exclude papers with only abstracts since we cannot get details about the research without reading a full-length article. Extended versions of conference papers present more research information, and hence, we exclude any duplicate documents and retain the journal papers.

\section{Inclusion criteria}

We include those studies that discuss the role of emerging technologies along with discussions on the COVID-19 pandemic. Also, we include research articles, cohort and intervention studies, case studies, editorial, and opinion papers published between December 1, 2019, and April 24, 2021.

\section{Search strategy}

We performed searches in the most popular digital data repositories (PubMed, Science Direct, and Springer) by using the keywords, "role of technology" OR "digital technology," AND "challenges of medical staff" OR "physicians" OR “nurses” AND “Corona Virus 2019” OR "COVID-19," OR “Corona Virus 2019” between December 1, 2019, and April 24, 2021. Titles, abstracts, and full-text papers with a discussion on the COVID-19 infection were initially chosen for this paper. To find relevant studies pertaining to the research topic, we used search strings without involving the biased search process. A review paper suggests that only a biased selection of published studies is performed. This study involves a broad research process based on predefined search keywords and strings.

\section{Study selection}

One of the researchers applied search strings to the chosen data repositories. The screening of papers was performed by examining the title and abstracts by an author $(\mathrm{MH})$, whereas, his colleague, author IG, conducted the screening of papers based on the full text of documents.

\section{Data extraction}

A bespoke form (see Table 1) was created in a Microsoft Word document. Data was extracted by two colleagues (MFP and IG). However, the quality of the included papers was not appraised due to the short time available for compiling the rapid review paper.

\section{Analysis}

Narrative analysis was performed by using the framework proposed in Downar and Seccareccia (2010), which focused on grouping the recommendations. Following data extraction and tabulation in Table 1, a narrative synthesis was conducted (Dabone et al. 2021). All the identified concepts and 
Table 1 Summary of the selected papers

\begin{tabular}{lll}
\hline Authors & Paper type & Summary of paper \\
\hline Henry and Lippi (2020) & Editorial paper & $\begin{array}{l}\text { Enhanced risk of the COVID-19 infection } \\
\text { is associated with chronic kidney disease } \\
\text { (CKD) }\end{array}$ \\
& &
\end{tabular}

Yang et al. (2020)

Huang et al. (2020)

Tey et al. (2020)

Sun et al. (2020)

Li et al. (2020)

Lu et al. (2020)

Ivanov (2020)

Ting et al. (2020)

Ienca and Vayena (2020) Commentary paper

Wang et al. (2020) Research paper

Singh et al. (2020)

Research paper

Smith et al. (2020)

Shaw et al. (2020)

Goldschmidt (2020)

Haleem et al. (2020)

Ozturk et al. (2020)

Ghai (2020)

Di Carlo et al. (2021)

Chang et al. (2021)

Chen et al. (2020)

Gibson et al. (2020)

Editorial paper

Research paper

Research paper

Research paper

Research paper

Research paper

Research paper

Research paper

Research paper

Research paper

Editorial paper

Research paper

Review paper

Review paper

Research paper

Review paper

Editorial paper
Short communication Public resources including 48 dental hospitals in China during the spread of COVID19 infection

Protection of the frontline people such as nurses and doctors during the COVID-19 epidemic

Challenges of COVID-19 outbreak in Singapore

Positive and negative emotions of frontline caregiving nurses

Innovative strategies for clinical pharmacists to fight against COVID-19 cal staff in China

Global supply chain during the crisis and the role of emerging technologies

The role of digital technology to combat the COVID-19 pandemic

Use of digital data to tackle the COVID-19 infection

Big data analytics helped in proactive testing of COVID-19 infection in Taiwan

IoT applications help researchers fight COVID-19 infection

Telemedicine technology implementation to increase control on COVID-19 infection during COVID-19 pandemic in East Asian countries

Telehealth usage for the care of children

Big data applications for COVID-19 infection

The role of AI technology, coupled with radiological imaging

Teledentistry role for resumption of dental practices during pandemic

Telepsychiatry role in bridging the distance in mental health diseases

Innovation in dental education during COVID-19 pandemic

Bio-sensing technology provides rapid testing of COVID-19 patients

Handheld ultrasound technology is reducing
Psychological effects on the frontline medi-

Findings and suggestions

Physicians need close monitoring of CKD patients for COVID-19 suspects

We found adverse effects on dental services in dental hospitals and widely used telehealth in the eastern region

We can suggest flexible and adjustable policies and protocols to reduce disease

Medical staff and nurses may adopt a better position in the oncology department for continuity of services

Nurses' negative emotions were controlled by using the self-coping styles

Telehealth facilities can better improve pharmacy services

An increasing number of COVID-19 cases were verified with psychological disorders outside of China

Simulation method can help in decisionmaking about long-term effects on the supply chain from COVID-19 pandemic

Digital technology can augment the public health strategies to handle the COVID-19 pandemic

Big data analytics combined with health records responded to the COVID-19 crisis

A population can be trained to provide accurate COVID-19 and other crises for their timely handling

COVID-19 infection symptoms were identified rapidly by IoT applications

Telemedicine technology helped researchers to complete an increased number of visits of patients

Governance, technology, and citizen behavior Emerging technologies had positive impacts on global pandemic control

Children engaged with adults had positive implications from the emerging technologies the risk of contamination
Digital data storing may help scientists to develop improved strategies for COVID-19 pandemic testing

DarkCovidNet model may have the potential for making an accurate and faster diagnosis

Incorporation of teledentistry into the routine dental practices

Integration of telepsychiatry with the technologies may open a new way of controlling mental health diseases

Pandemic has a lot impact on dental education, and innovative technology is required to improve dental education

Bio-sensing can be incorporated with other technologies to increase reliability

The emergent technology has better results than the stethoscope and chest radiography 
Table 1 (continued)

\begin{tabular}{|c|c|c|c|}
\hline Authors & Paper type & Summary of paper & Findings and suggestions \\
\hline Lamprou (2020) & Research paper & $\begin{array}{l}\text { Additive manufacturing (AM), microfluidics } \\
\text { (MF), and microelectromechanical systems } \\
\text { (MEMS) have roles in fighting against the } \\
\text { COVID-19 pandemic }\end{array}$ & $\begin{array}{l}\text { All these technologies provide cost-effective } \\
\text { solutions during the emerging pandemic }\end{array}$ \\
\hline Ahmed et al. (2021) & Research paper & $\begin{array}{l}\text { Material technology has a contribution to } \\
\text { reducing damage from the COVID-19 } \\
\text { pandemic }\end{array}$ & $\begin{array}{l}\text { Materials can be developed to provide comfort } \\
\text { to the patient during breathing }\end{array}$ \\
\hline Chintagunta et al. (2021) & Review paper & $\begin{array}{l}\text { Nanotechnology technology and its role dur- } \\
\text { ing the COVID-19 pandemic }\end{array}$ & $\begin{array}{l}\text { Nanotechnology may have implications to } \\
\text { sterilize the medicine to control COVID-19 } \\
\text { infection }\end{array}$ \\
\hline Loli et al. (2021) & Research paper & $\begin{array}{l}\text { Telementoring with the help of WhatsApp } \\
\text { messaging }\end{array}$ & $\begin{array}{l}\text { Smartphone Telementoring is a useful tool for } \\
\text { educational training to acquire laparoscopic } \\
\text { skills }\end{array}$ \\
\hline Haleem et al. (2021) & Research paper & $\begin{array}{l}\text { The role of AI in dealing with cardiac } \\
\text { patients }\end{array}$ & AI helped visualize cardiac anomalies \\
\hline Intawong et al. (2021) & Research paper & $\begin{array}{l}\text { The role of application technology in com- } \\
\text { bating the COVID-19 pandemic }\end{array}$ & $\begin{array}{l}\text { Application technology promoted COVID-19 } \\
\text { patients' health and enhanced their satisfac- } \\
\text { tion }\end{array}$ \\
\hline
\end{tabular}

themes were arranged and grouped to synthesize significant themes. Two of four authors (MH and SRJ) were responsible for reviewing and discussing major identified themes.

\section{Results}

Summaries of the important studies are presented in Table 1. In the following section, we present the results and discussions of the reviewed studies. The first part of the section is aimed to present the results and discussions with regard to the safety challenges of frontline medical staff, and the second part presents results and discussions regarding emerging technologies and their role in the COVID-19 pandemic situation.

Table 1 presents a summary of each chosen study in this rapid review paper. The central idea presented in each chosen study is stated, along with the authors' list and paper type. We also include findings and suggestions from reviewed literature. As mentioned earlier in the inclusion criteria, research articles, including editorial papers, short communication, commentary papers, review papers, and research papers have been included in this paper, and we did not exclude any published works that discussed the research topic.

As shown in Fig. 2, 18 papers (or 64\%) are research papers, four papers (or 14\%) are editorial papers, four papers (or 14\%) are review papers, one paper (or $4 \%$ ) is commentary paper, and one article (or 4\%) is a short communication paper. Publishing trends on COVID-19 since December 2019 have been evidenced from research papers, including original research studies, case reports, proposed models, and review papers. In summary, it can be considered that the COVID-19 topic is in its initial phases of research because emerging literature is not totally focused on large and extended studies on COVID-19 prevention models and approaches.

In the following, we present results regarding identified emerging technologies as role players during pandemic situation.

Figure 3 presents the recently identified emerging technologies and their role in the prevailing COVID-19 pandemic situation. We have identified 11 major technologies, which have been studied in the published works. At this stage, no strong relationship between the recognized technologies or with medical technology has been established. However, the role of each technology shown in Fig. 3 is discussed in relation to the COVID-19 pandemic. Therefore, the mind map, as illustrated in Fig. 3, can be further extended to the applications of the identified technologies. Earlier, we have elaborated on the role of each identified technology; we also require the proposals of new approaches with the recognized technologies. The desired methods can be applied to the COVID-19 pandemic to minimize or reduce its adverse impacts on human lives. Among the identified technologies, the role of AI, IoT, telemedicine, and telehealth is obvious in comparison with the rest of the technologies.

Figure 4 shows the mind map of the top 4 technologies, which include AI, IoT, telemedicine, and telehealth. Much has been known about the applications of AI and IoT technologies. Therefore, researchers can easily apply them to the COVID-19 pandemic situation to avert big losses. The lack of specialized physicians is a major challenge, and the proposal of AI techniques is bridging the gaps in the correct diagnosis of COVID-19 disease. In this regard, the AI-based model is helping physicians to detect and classify COVID-19 
Fig. 2 Research article type

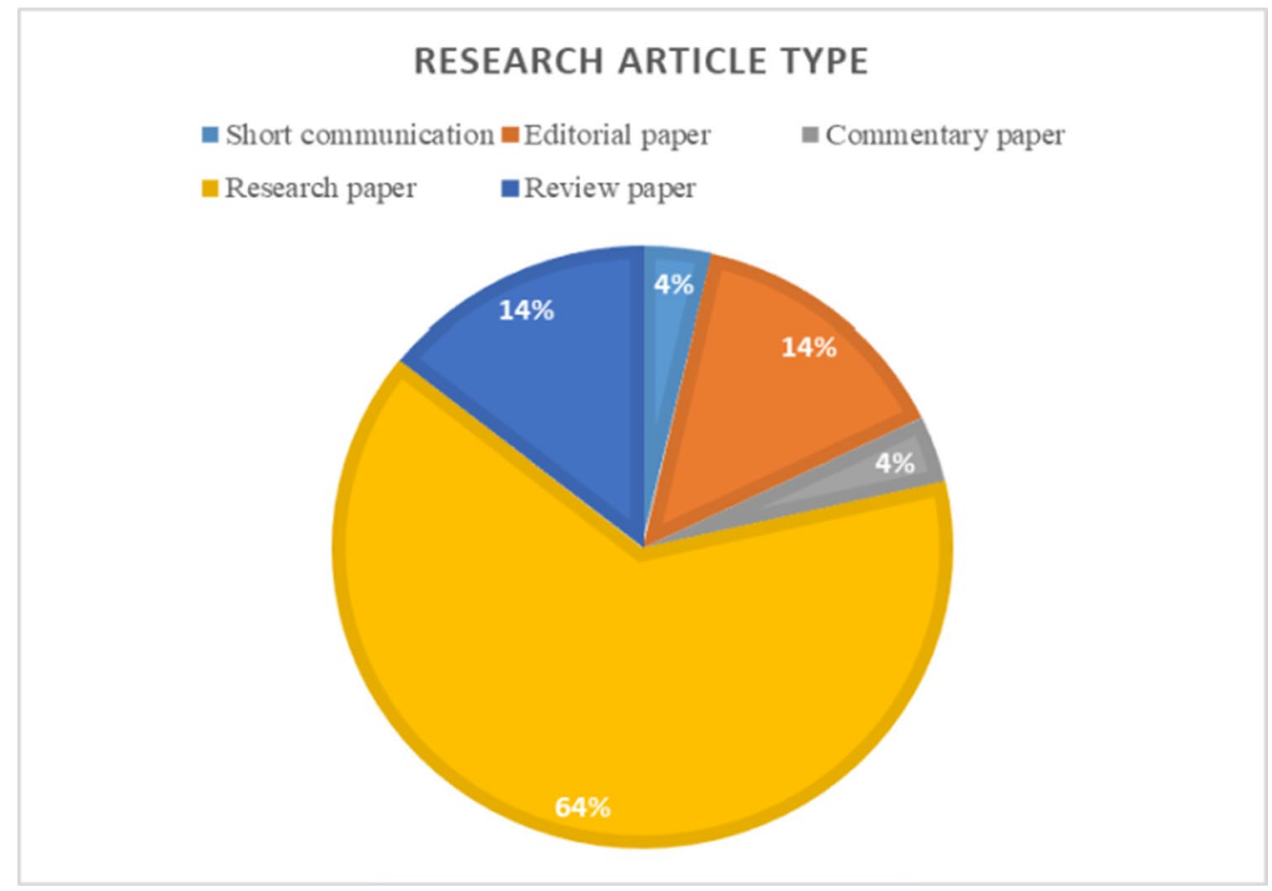

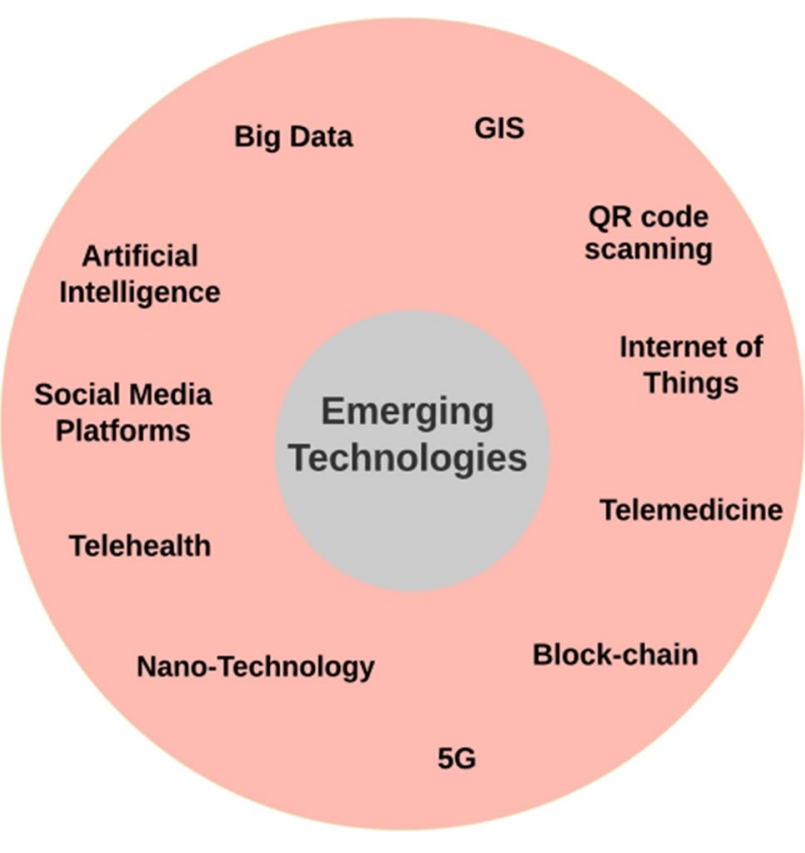

Fig. 3 Mind map of emerging technologies

patients (Ozturk et al. 2020; Ucar and Korkmaz, 2020). The model is efficient in using the chest X-ray images of people suspected of having the COVID-19 infection. Ribas et al. (2021) emphasized the restructuring of the diagnostic imaging department in Spain to enhance the frontline battling against the COVID-19 pandemic. This was required to meet the challenges of the COVID-19 pandemic.
Table 2 illustrates the challenges faced by frontline medical staff at workplaces. We identified a number of studies, which highlight several challenges for the frontline medical staff. Among these challenges, the shortage of PPEs is a major concern for physicians and nurses working in COVID19 infection departments. Every challenge has adverse effects on the persons involved in treating patients exposed to the COVID-19 infection.

\section{Discussion}

\section{Safety challenges of frontline medical staff}

Researchers stated that patients with "chronic kidney disease" (CKD) have more exposure to the COVID-19 infection. The clinical staff and particularly physicians are usually involved in the close monitoring of patients with CKD (Henry and Lippi, 2020). CKD seems to be more associated with the risk of severe COVID-19 disease. Therefore, CKD patients need extra care from medical staff to minimize the exposure to the virus. The role of physicians is worth mentioning here because the timely detection of signs of the COVID-19 infection can save the lives of suspected as well as many other people. It has been seen that people with diabetes and kidney diseases have higher chances of exposure to COVID-19.

A short communication paper highlights the provision of health services during the COVID-19 pandemic in China (Yang et al. 2020). The paper is focused on the role of professionals and online services in emergency and 


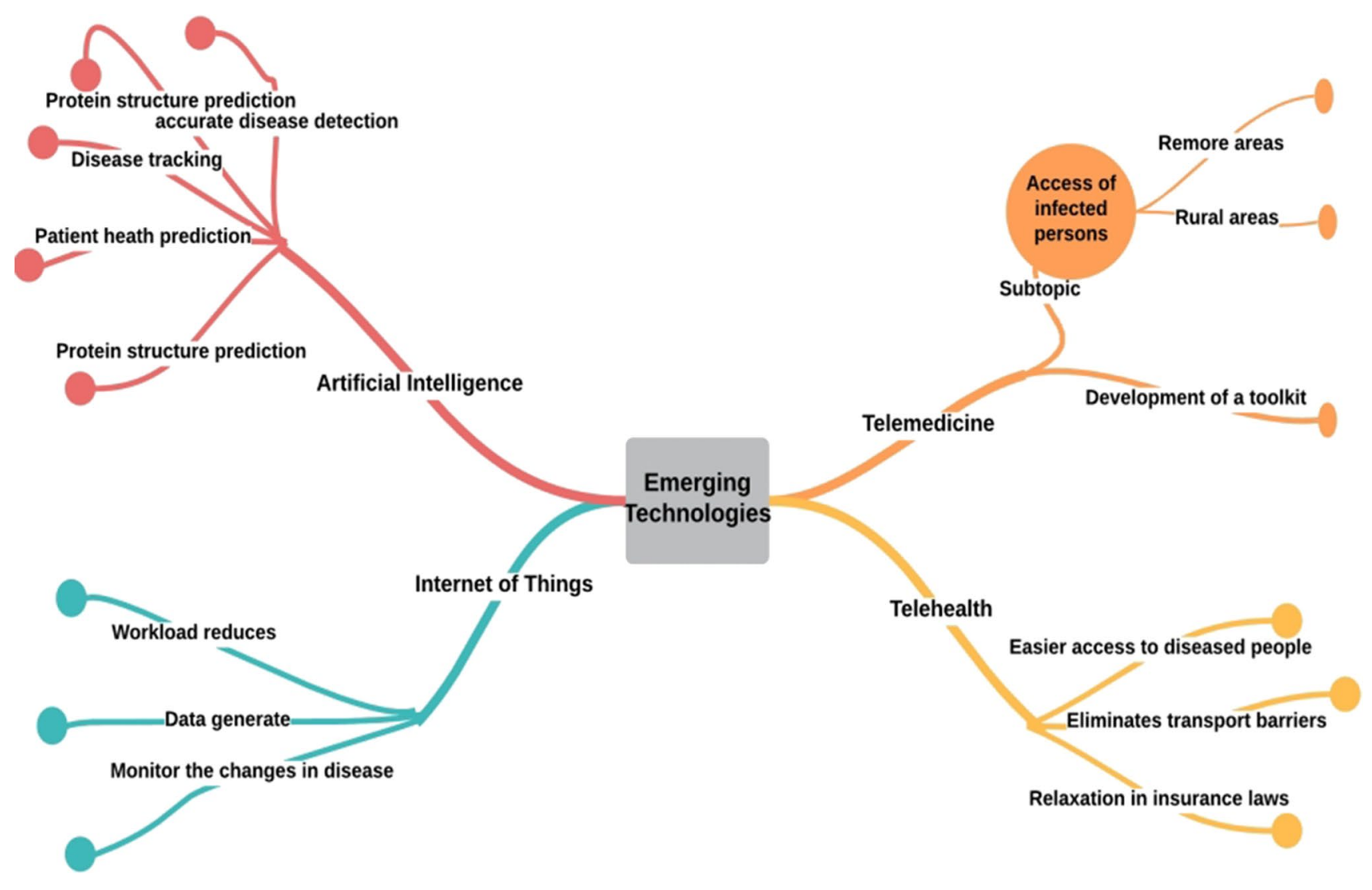

Fig. 4 Emerging technologies during the COVID-19 pandemic

Table 2 Safety challenges and their consequences

\begin{tabular}{lllc}
\hline Sr. no & Safety challenge & Consequences & References \\
\hline 1 & Shortage of PPEs & Increase in virus transmission rate & $\begin{array}{c}\text { Tempe et al. (2020); } \\
\text { Ertl-Wagner et al. } \\
(2020)\end{array}$ \\
2 & Unavailability of disinfection solution & May increase the infection rate & Tempe et al. (2020) \\
3 & Close monitoring of patients with CKD & Increase in time to look after patients & Henry and Lippi (2020) \\
4 & Fatigue, helplessness, discomfort, stress, & Deteriorate the workers' health & Sun et al. (2020) \\
5 & and depression & Increase the virus transmission to healthcare workers & Huang et al. (2020) \\
6 & Exposure of direct contact & Inappropriate use of sources to prevent COVID-19 infection & Dunlop et al. (2020) \\
\hline
\end{tabular}

nonemergency situations in China. To combat the infection, the majority of the hospitals suspended nonemergency treatments and provided only emergency services. Eventually, the role of dental physicians changed to online services, and a significant proportion $(69 \%)$ of physicians offered free online services. Moreover, the penetration of technology in the prevention of COVID-19 infection was higher in the eastern part of China in contrast to the western and central regions. The implications of the use of nonemergency dental services might be a leading effect on the increased dental care issues in the future.
During the outbreak of the COVID-19 pandemic, the protection of medical staff, including frontline physicians and nurses, is an issue that should be given the utmost attention and importance. Huang et al. (2020) stated that more than 3000 medical staff were infected by the coronavirus in China. Direct contact with COVID-19 infected people might be the cause of high infection rates among nurses in China. As a result, several young medical staff members died. As such, securing the lives of frontline medical staff members has proven to be a challenging task. Based on the safety challenges of frontline medical staff, 
it is suggested that protocols and guidelines need to be designed for the protection of physicians, nurses, and the rest of the medical staff who are fighting the COVID-19 disease.

Moreover, frontline nurses experienced positive and negative psychological emotions. In a recently published work, researchers identified that caregiver nurses faced the challenges of fatigue, helplessness, and discomfort due to highly intensive work (Sun et al. 2020). Potential stress and depression are reported among the nurses because they face the fear and concerns of patients' family members. Consequently, they show positive emotions after negative emotions have occurred. To combat the arising situation of medical staff and particularly nurses with insomnia or anxiety, they are highly encouraged to seek help from psychotherapists. In addition to this, they have been advised to avoid unnecessary contact, which is crucial for the prevention of COVID-19 infection through cross-transmission.

In comparison with the administrative staff, medical staff were more prone to significant depression, fear, and anxiety. It has been stated that medical staff suffered the issues, as mentioned earlier, twice as much as the administrative staff ( $\mathrm{Lu}$ et al. 2020). Limited studies have focused on the psychological effects of COVID-19 on the medical staff. It might be due to the lesser amount of available data on the topics of COVID-19 and mental stress. Physicians and nurses participating in the treatment of COVID-19 patients became more susceptible to psychological effects (Chen et al. 2021). Health researchers and other academic researchers rely more on the news from different sources. Moreover, researchers also worry about close contact with the medical staff and COVID-19 patients.

So far, we have discussed the role of medical staff and their safety challenges with regard to the COVID-19 infection from the perspective of China. In our research, we have included a paper that is based on the challenges of the COVID-19 outbreak in Singapore (Tey et al. 2020). Based on the history of the "severe acute respiratory syndrome" (SARS) coronavirus and the H1N1 epidemic, the Singapore government was well prepared to fight the virus. They used swift measures to break the chain of virus transmission. Since the death rate among cancer patients and diabetics remained higher for COVID-19, the medical staff and cancer patients were provided maximum protection against the COVID-19 epidemic.

Other than the safety challenges of medical staff, we include an overview of the emerging technologies as researched from the published papers, as follows:

\section{Role of emerging technologies during the outbreak of the COVID-19 pandemic}

\section{Big data and geographic information systems}

Big data and geographic information system (GIS) technologies played a vital role in generating the aggregated big data from multiple sources (Zhou et al. 2020). Besides, spatial tracking of confirmed death cases and regional transmission of the virus and spatial segmentation of virus epidemic information have been supportive in decision-making and have helped the relevant parties in taking adequate measures in the prevailing COVID-19 situation. Geographic information systems in this regard are more productive in data preparation, map production, and model construction with the appropriate route of technology. However, we still face challenges in adjusting technologies to prevent the widespread outbreak of the COVID-19 epidemic. For this, we need to propose and implement strategies that can provide extra benefits to users in controlling the transmission of the virus to different regions. Potential users of the technologies may include health workers. Among health workers, physicians and nurses are the most important users.

The Taiwanese government integrated the health insurance database with the custom databases of the travel history of users to identify cases. This way, they created big data analytics. Haleem et al. (2020) pointed out the immediate need for increasing the capacity of data storage of COVID19 infection cases. The data stored can be further used to understand the means of spreading the virus and can be used for further research and development about the virus. Due to the unavailability of ample data storage space, essential data may be lost. Therefore, big data needs to be used to analyze the differences, patterns, trends, and associations in the COVID-19 infection cases. Later, this data analysis can be used to propose techniques to control viral diseases similar to the COVID-19 infection.

\section{QR code scanning}

QR code scanning is another valuable addition to the use of digital technologies that helped in the classification of travelers based on their travel history and infection risk in the past few days. More countries need to gear up to use such digital technologies in fighting against the COVID-19 pandemic (Ienca \& Vayena 2020; Wang et al. 2020). The ultimate impact of the aforementioned technologies remained productive in the classification of travelers with low to high risks. Short message service (SMS) was used to update travelers with low risk for their fast immigration clearance, while those with high risks were asked to be quarantined at homes. 


\section{Artificial intelligence (AI)}

Ivanov (2020) in his research pointed out the potential of digital technologies in controlling the rapid increase of COVID-19 worldwide. For instance, the supply chain system can be further improved during the crisis by doing innovative work on the available data. Among the many emerging technologies, areas with a particular focus can be artificial intelligence (AI), data analytics, and machine learning. Although the role of each area is identified in the literature, it is yet unknown how these technologies can be applied to the supply chain area in a realistic manner in the epidemic situation. Moreover, in recent research, Haleem et al. (2021) identified eleven major AI applications, and they suggested predicting the COVID-19 patients from cardiac-based approaches.

Shaffiee Haghshenas et al. (2020) pointed out the adverse impacts of COVID-19 on society, the environment, and economics. Their research prioritizes the impacting factors on the environment. To prioritize the impacting factors, artificial neural networks (ANN) and differential evolution (DE) algorithms were used. Furthermore, two ANN models, including the ANN-PSO and ANN-DE, were compared with regard to their accuracies. The former model of ANN with particle swarm optimization (PSO) showed better results in prioritizing variables for the prediction of confirmed COVID-19 cases. Based on the research mentioned earlier, other algorithms in the domain of AI can be selected for feature selection of different urban and climate parameters in future works.

Deep learning models are widely used to explore the intricate hidden patterns of images. In comparison with the conventional machine learning (ML) models, deep learning models show a higher accuracy in the detection of image patterns. The convolutional neural network (CNN) model is mainly used in different research areas. Vaid et al. (2020) developed a CNN model to predict the disease categorization and structural abnormalities precisely. Both of these challenges are key to uncovering the hidden patterns. The CNN model remained useful for the detection of COVID-19 patients' anterior-posterior radiographs. The main advantage of using the CNN model is that, due to the automated detection of structural abnormalities in chest $\mathrm{X}$-rays, manual interaction by radiologists has been minimized. As the CNN model shows a high prediction accuracy, policymakers need to take note of such alternatives to find an appropriate path during pandemic conditions.

\section{Internet of things (IoT) and blockchain}

Internet of things and blockchain are other major technologies, which can be applied to tackle clinical issues and disease in times of crisis. Ting et al. (2020) explored the applications of the technologies, as mentioned earlier. They stated that IoT is a better platform that allows the public and private health agencies to access the necessary data for monitoring the COVID-19 disease. In this way, it can efficiently monitor the changing situation of COVID-19 patients (Singh et al. 2020). The latter mentioned research highlights the tracking of infection of individuals. Furthermore, it reduces the workload on the medical staff. Worldometers and centers for system science and engineering are the prime examples of IoT, which are helping the health professionals with realtime updates on the COVID-19 infection, in addition to helping in tracking the real-world map of COVID-19 infection. For modeling studies on viral activities, IoT is also making its contribution to guide policymakers in preparing them against the outbreak.

Internet of medical things (IoMT) has been deployed with other approaches to curb the spread of the pandemic. This may improve the safety of frontline staff and decrease the mortality rate. IoMT emerged from the merger of AI, blockchain, and big data technologies (Aman et al. 2020) . It would be useful if security includes a major element in its design that may ensure the privacy and safety of humanity.

\section{Social media platforms}

WhatsApp, Facebook, and Twitter as social media platforms are playing their key role in informing the users and clarifying the uncertainties regarding the actual cases, deaths, and recovered cases around the world. Contrary to it, de Bruin et al. (2020) stated that due to the people being increasingly connected across the globe because of social media, there is a higher probability of spreading misinformation over the social media platforms. This creates problems for policymakers in sharing the current and updated information with users and maintaining best practices. Risk mitigation policies cannot bring the expected results. Dsouza et al. (2020) recommended that social media platforms should be used with great care to promote the positive mental health of patients and normal people to combat the COVID-19 pandemic. Morshed et al. (2021) emphasized Twitter data analysis from real-time ride-hailing services' users. They aimed to know the customers' behavioral patterns to improve the business model of ride-hailing services. It is vital to know public sentiments and their reactions, and social media has a good share in reducing public concerns. However, the prevailing situation of the COVID-19 pandemic has a significant impact on the services.

\section{Telemedicine and $5 \mathrm{G}$ technology}

Telemedicine is aimed at expanding the opportunities for healthcare professionals to access the rural and remote areas' populations infected with the COVID-19 infection 
(Smith et al. 2020). Telemedicine relies on technology to benefit the health professionals and target population in the prevailing situation of the COVID-19 infection. Due to the increasing load on health professionals and urgency in treating infected people, while telemedicine usage has increased, its users are largely inexperienced. To overcome this lack and gap in the use of telemedicine, Smith et al. (2020) proposed a method of implementing a telemedicine platform. They developed a toolkit along with its eight essential components. The method proposed in the latter study reduces the traveling cost of approaching populations affected with the COVID-19 infection.

It also increases the number of visits to healthcare professionals. The USA, in response to the pandemic, relaxed several restrictions and provided additional funding with regard to telemedicine (Contreras et al. 2020). It is expected that telemedicine and telesurgery will become matured because of the fact that consumers' health devices would soon be connected with $5 \mathrm{G}$ data connectivity. The main advantage of $5 \mathrm{G}$ technology is its high-speed data transmission in comparison with $4 \mathrm{G}$ technology. As a result of the high-speed data transfers, latency between an input of surgery and anticipated motion can be decreased. Telemedicine is also used to evaluate the diagnosis and treatment of patients after discharge when social distancing is required. As a result, the admission rate in hospitals decreases (Nan et al. 2021). Critical diagnostic and monitoring of remote patients are other aspects of telemedicine that involve smartphone, Bluetooth, and global positioning system technologies. One of the significant challenges is the appropriate technology needed for telemedicine, i.e., access to the internet. Tandon et al. (2021) stated that many Indian COVID-19 patients could not access highspeed internet in their homes. Technology illiteracy and resistance to a new system were identified as other significant obstacles to the adoption of telemedicine.

\section{Telehealth}

In a recently published research, Bojdani et al. (2020) have shown that telehealth is widely being used throughout the world, and technology is supporting health professionals with regard to outpatient care. Health professionals adapting to telehealth have faced difficulties in adjusting to webcambased services. Trained physicians work from their homes regarding using telehealth and add their increasing support to combat the COVID-19 pandemic. On the other hand, patients also face difficulties in accessing the aforementioned technology because their smartphones have no access to faster internet. Overall, many COVID-19 patients have benefited from using this technology. Moreover, patients have eliminated transportation barriers. Legal constraints have been faced while benefiting children of different ages from telehealth. These legal constraints cover issues with licensing and gaps in insurance policy coverage (Goldschmidt 2020). Federal and state governments in the USA were asked to relax telehealth rules to support the children from rural areas and across the state lines. Therefore, the COVID-19 pandemic exercised a paradigm shift in telehealth laws with regard to insurance reimbursement.

\section{Nanotechnology}

Nanotechnology and its emerging material are contributing to reducing the size of COVID-19 infection testing systems. The emerging nanotechnology is expected to help in reducing the size of materials required by the expected patients. This process makes the process of COVID-19 infection testing easier and practical (AlMaadeed 2020). This process is not so matured yet and requires a worldwide contribution to the improvement of human health by combating and preventing the disease outbreak.

Shaw et al. (2020) also highlighted the role of emerging technologies, including AI, big data, robotics, 5G, blockchain, and automated vehicles, at the advanced phase of the technological intervention. Researchers in the research emphasized the appropriate linking of the medical technologies with the earlier mentioned technologies. However, the means of integrating emerging technologies with medical technology have not been mentioned. Therefore, this topic must be considered for research in future works.

\section{Conclusion and implications}

The safety of medical staff can be negatively affected by the extreme pressure of COVID-19 patients and their families. Medical personnel, particularly frontline nurses, have both negative and positive emotions during the COVID-19 epidemic. The role of technology in the emerging viral situation has been identified in this rapid review paper. Big data, AI, IoT, QR code scanning, social media platforms, 5G, blockchain, nanotechnology, telehealth, and telemedicine platforms were identified as key role-playing technologies in this rapid review paper. The findings of this rapid review study further suggest proposing policies and guidelines to improve the health and safety of frontline medical staff, in future research works.

Below, we present the implications from existing literature regarding the COVID-19 pandemic:

- To win the war against the COVID-19 pandemic, it is recommended that all necessary resources need to be provided to frontline medical staff, just as a nation supports 
and encourages its soldiers during wartime (Vaishya and Vaish 2020).

- Moreover, safety at the core of frontline medical staff and a team-based approach is recommended with some guidelines (Takhar et al. 2020). According to these guidelines, no team member is allowed to work more than 1 day per week in the critical situation of the COVID-19 pandemic. Rotation of staff can minimize the exposure to viral disease and can also ensure the consistency in the expertise of team members across a week.

- Proper and practical training of physicians, nurses, and other medical staff is necessary in all cases; and more consideration should be given to the training and practice of the frontline medical staff handling high-risk patients (Mahmud et al. 2020).

- Web technology is recommended, which can help in bringing visitors to the COVID-19 patient room by using iPads and thus reducing visitors' physical load on hospitals (Kapoor et al. 2020).

- For real information exchange between health workers, ministries, and administrative portals, interactive communication tools can be used. It can help healthcare staff working in remote areas to fight the COVID-19 pandemic by enabling them to share information with the higher authorities.

- In order to overcome the shortage of PPEs, the use of one mask for several procedures has been considered. However, the sterilization of reusable PPEs is mandatory.

COVID-19 has been found a highly contagious disease. In the third week of April 2021, 5.2 million new cases were reported along with 83,000 deaths. Except for European regions, the COVID-19 pandemic has been reported higher in other areas, particularly India (World Health Organization 2021). Physicians, healthcare workers, and nurses still have an enormous threat from viruses and remain more susceptible to the infection. It is believed that emerging technologies have positive effects on the health of medical staff.

\section{Declarations}

Ethics approval It is stated that our research does not involve experiments on humans or animals. For this type of research, formal consent is not required.

Conflict of interest The authors declare no competing interests.

\section{References}

Ahmed J, Alenezi H, Edirisinghe U, Edirisinghe M. Perspective: COVID-19; emerging strategies and material technologies.
Emergent Mater. 2021;4(1):3-8. https://doi.org/10.1007/ s42247-021-00173-x.

AlMaadeed MA. Emergent materials and Industry 4.0 contribution toward pandemic diseases such as COVID-19. Emergent Mater. 2020;1-2. https://doi.org/10.1007/s42247-020-00102-4.

Aman AHM, Hassan WH, Sameen S, Attarbashi ZS, Alizadeh M, Latiff LA. IoMT amid COVID-19 pandemic: application, architecture, technology, and security. J Netw Comput Appl. 2020;174:1-19. https://doi.org/10.1016/j.jnca.2020.102886.

Bansal P, Bingemann TA, Greenhawt M, Mosnaim G, Nanda A, Oppenheimer $\mathrm{J}, \ldots$ \& Shaker M. Clinician Wellness during the COVID-19 pandemic: extraordinary times and unusual challenges for the allergist/immunologist. The Journal of Allergy and Clinical Immunology: In Practice. 2020. https://doi.org/10.1016/j.jaip. 2020.04.001

Bojdani E, et al. COVID-19 Pandemic: impact on psychiatric care in the United States, a review. Psychiatry Res. 2020. https://doi. org/10.1016/j.psychres.2020.113069.

Chang TY, Hong G, Paganelli C, Phantumvanit P, Chang WJ, Shieh YS, Hsu ML. Innovation of dental education during COVID19 pandemic. J Dent Sci. 2021;16(1):15-20. https://doi.org/10. 1016/j.jds.2020.07.011.

Chen L, Zhang G, Liu L, \& Li Z. Emerging biosensing technologies for improved diagnostics of COVID-19 and future pandemics. Talanta. 2020;225:1-10. https://doi.org/10.1016/j.talanta. 2020.121986.

Chen R, Sun C, Chen JJ, Jen HJ, Kang XL, Kao CC, Chou KR. A large-scale survey on trauma, burnout, and posttraumatic growth among nurses during the COVID-19 pandemic. Int J Ment Health Nurs. 2021;30(1):102-16. https://doi.org/10.1111/ inm.12796.

Chintagunta AD, M SK, Nalluru S, NS SK. Nanotechnology: an emerging approach to combat COVID-19. Emergent Mater. 2021;1-12. https://doi.org/10.1007/s42247-021-00178-6.

Contreras CM, Metzger GA, Beane JD, Dedhia PH, Ejaz A, Pawlik TM. Telemedicine: patient-provider clinical engagement during the COVID-19 pandemic and beyond. J Gastrointest Surg. 2020;24:1692-7. https://doi.org/10.1007/s11605-020-04623-5.

Clifton VL, Flathers KM, Brigham TJ. COVID-19-background and Health Sciences Library response during the first months of the pandemic. Med Ref Serv Q. 2021;40(1):1-10. https://doi.org/10. 1080/02763869.2021.1873611.

Dabone C, Mbagwu I, Muray M, Ubangha L, Kohoun B, Etowa E, ... \& Etowa J. Global food insecurity and African, Caribbean, and Black (ACB) populations during the COVID-19 pandemic: a rapid review. J Racial Ethn Health Disparities. 2021;1-16. https://doi. org/10.1007/s40615-021-00973-1

de Bruin YB, Lequarre AS, McCourt J, Clevestig P, Pigazzani F, Jeddi MZ, ... \& Goulart M. Initial impacts of global risk mitigation measures taken during the combatting of the COVID-19 pandemic. Saf Sci. 2020;104773. https://doi.org/10.1016/j.ssci. 2020.104773

Di Carlo F, Sociali A, Picutti E, Pettorruso M, Vellante F, Verrastro V, ... \& di Giannantonio M. Telepsychiatry and other cutting-edge technologies in COVID-19 pandemic: bridging the distance in mental health assistance. Int J Clin Pract. 2021;75(1). https://doi. org/10.1111/ijcp.13716

Dsouza DD, Quadros S, Hyderabadwala, Z. J., \& Mamun, M. A. Aggregated COVID-19 suicide incidences in India: fear of COVID-19 infection is the prominent causative factor. Psychiatry Research, 2020. 113145. https://doi.org/10.1016/j.psychres. 2020.113145

Downar J, Seccareccia D, Associated Medical Services, Inc Educational Fellows in Care at the End of Life. Palliating a pandemic: "all patients must be cared for." J Pain Symptom Manage. 
2010;39(2):291-5. https://doi.org/10.1016/j.jpainsymman.2009. 11.241.

Dunlop A, Lokuge B, Masters , Sequeira M, Saul P, Dunlop G, ... \& Lintzeris N. Challenges in maintaining treatment services for people who use drugs during the COVID-19 pandemic. Harm Reduct J. 2020;17:1-7. https://doi.org/10.1186/s12954-020-00370-7

Ertl-Wagner BB, Lee W, Manson DE, et al. Preparedness for the COVID-19 pandemic in a tertiary pediatric radiology department. Pediatr Radiol. 2020. https://doi.org/10.1007/ s00247-020-04704-2.

Ghai S. Teledentistry during COVID-19 pandemic. Diabetes Metab Syndr. 2020;14(5):933-5. https://doi.org/10.1016/j.dsx.2020.06. 029.

Gibson LE, Bittner EA, Chang MG. Handheld ultrasound devices: an emerging technology to reduce viral spread during the COVID-19 pandemic. Am J Infect Control. 2020;48:968-9. https://doi.org/ 10.1016/j.ajic.2020.05.041.

Goldschmidt K. The COVID-19 pandemic: technology use to support the wellbeing of children. J Pediatr Nurs. 2020. https://doi.org/10. 1016/j.pedn.2020.04.013.

Haghani M, Bliemer MC, Goerlandt F, Li J. The scientific literature on coronaviruses, COVID-19 and its associated safety-related research dimensions: a scientometric analysis and scoping review. Saf Sci. 2020;129:104806. https://doi.org/10.1016/j.ssci.2020. 104806.

Haleem A, Javaid M, Khan I, Vaishya R. Signifcant applications of big data in COVID-19 pandemic. Indian J Orthop. 2020. https://doi. org/10.1007/s43465-020-00129-z.

Haleem A, Javaid M, Singh RP, Suman R. Applications of artificial intelligence (AI) for cardiology during COVID-19 pandemic. Sustainable Operations and Computers. 2021. https://doi.org/10. 1016/j.susoc.2021.04.003.

Hasnain M, Pasha MF, Ghani I. Combined measures to control the COVID-19 pandemic in Wuhan, Hubei, China: a narrative review. Journal of Biosafety and Biosecurity. 2020;2(2):51-7. https://doi. org/10.1016/j.jobb.2020.10.001.

Henry BM, Lippi G. Chronic kidney disease is associated with severe coronavirus disease 2019 (COVID-19) infection. Int Urol Nephrol. 2020;52:1193-4. https://doi.org/10.1007/s11255-020-02451-9.

Holmes DR. Breast cancer care during a pandemic: an opportune time for cryoablation? Breast Cancer Res Treat. 2020;183(3):515-21. https://doi.org/10.1007/s10549-020-05724-0.

Huang L, Lin G, Tang L, Yu L, Zhou Z. Special attention to nurses' protection during the COVID-19 epidemic. Crit Care. 2020;24(110):1-3. https://doi.org/10.1186/s13054-020-2841-7.

Ienca M, Vayena E. On the responsible use of digital data to tackle the COVID-19 pandemic. Nat Med. 2020;26(4):463-4. https://doi. org/10.1038/s41591-020-0832-5.

Intawong $\mathrm{K}$, Olson $\mathrm{D}$, Chariyalertsak S. Application technology to fight the COVID-19 pandemic: lessons learned in Thailand. Biochem Biophys Res Commun. 2021;534:830-6. https://doi.org/10.1016/j. bbrc.2020.10.097.

Ivanov D. Predicting the impacts of epidemic outbreaks on global supply chains: a simulation-based analysis on the coronavirus outbreak (COVID-19/SARS-CoV-2) case. Transp Res E: Logist Transp Rev. 2020;136:101922. https://doi.org/10.1016/j.tre.2020. 101922.

Javaid M, Haleem A, Vaishya R, Bahl S, Suman R, Vaish A. Industry 4.0 technologies and their applications in fighting COVID-19 pandemic. Diabetes Metab Syndr: Clinical Research \& Reviews. 2020. https://doi.org/10.1016/j.dsx.2020.04.032.

Kapoor A, Guha S, Das MK, Goswami KC, Yadav R. Digital healthcare: the only solution for better healthcare during COVID-19 pandemic? Indian Heart J. 2020. https://doi.org/10.1016/j.ihj. 2020.04.001.
Lamprou DA. Emerging technologies for diagnostics and drug delivery in the fight against COVID-19 and other pandemics. Expert Rev Med Devices. 2020;17(10):1007-12. https://doi.org/10.1080/ 17434440.2020 .1792287$.

Li H, Zheng S, Liu F, Liu W, Zhao R. Fighting against COVID-19: innovative strategies for clinical pharmacists. Res Social Adm Pharm. 2020;17(1):1813-8. https://doi.org/10.1016/j.sapharm. 2020.04.003.

Liberati A, Altman DG, Tetzlaff J, Mulrow C, Gøtzsche PC, Ioannidis JP, ... \& Moher D. The PRISMA statement for reporting systematic reviews and meta-analyses of studies that evaluate health care interventions: explanation and elaboration. Journal of clinical epidemiology. 2009;62(10), e1-e34. https://doi.org/10. 1136/bmj.b2700.

Loli YT, Huamán MDCT, Medina SC. Telementoring of in-home real-time laparoscopy using whatsapp messenger: an innovative teaching tool during the COVID-19 pandemic. A cohort study. Ann Med Surg. 2021;62:481-4. https://doi.org/10.1016/j.amsu. 2021.01.085.

Lu W, Wang H, Lin Y, Li L. Psychological status of medical workforce during the COVID-19 pandemic: a cross-sectional study. Psychiatry Res. 2020;288:112936. https://doi.org/10.1016/j.psych res.2020.112936.

Mahmud E, Dauerman HL, Welt FG, Messenger JC, Rao SV, Grines C, Mattu A, Kirtane AJ, Jauhar R, Meraj P, Rokos IC, Rumsfeld JS, Henry TD. Management of acute myocardial infarction during the COVID-19 pandemic. J Am Coll Cardiol. 2020. https://doi. org/10.1016/j.jacc.2020.04.039.

Morales-Narváez E, Dincer C. The impact of biosensing in a pandemic outbreak: COVID-19. Biosens Bioelectron. 2020;163:112274. https://doi.org/10.1016/j.bios.2020.112274.

Moher D, Liberati A, Tetzlaff J, Altman DG. Preferred reporting items for systematic reviews and meta-analyses: the PRISMA statement. Int J Surg. 2010;8(5):336-41. https://doi.org/10.1016/j.jclinepi. 2009.06.005.

Morshed SA, Khan SS, Tanvir RB, Nur S. Impact of the COVID-19 pandemic on ride-hailing services based on large-scale Twitter data analysis. J Urban Manag. 2021. https://doi.org/10.1016/j. jum.2021.03.002.

Nan J, Jia R, Meng S, Jin Y, Chen W, Hu H. The impact of the COVID19 pandemic and the importance of telemedicine in managing acute ST segment elevation myocardial infarction patients: preliminary experience and literature review. J Med Syst. 2021;45(1):19. https://doi.org/10.1007/s10916-020-01703-6.

Ozturk T, Talo M, Yildirim EA, Baloglu UB, Yildirim O, Acharya UR. Automated detection of COVID-19 cases using deep neural networks with X-ray images. Comput Biol Med. 2020;121:103792. https://doi.org/10.1016/j.compbiomed.2020.103792.

Ribas D, Del Riego J, Perendreu J. Role of diagnostic imaging technologists during the COVID-19 pandemic: the importance of organization and planning in the first line. Radiología (english Edition). 2021;63(1):50-5. https://doi.org/10.1016/j.rx.2020.09.006.

Shaffiee Haghshenas S, Pirouz B, Shaffiee Haghshenas S, Pirouz B, Piro P, Na KS, ... \& Geem Z. W. Prioritizing and analyzing the role of climate and urban parameters in the confirmed cases of COVID-19 based on artificial intelligence applications. Int J Environ Res Public Health;2020:17(10), 3730. https://doi.org/10.3390/ ijerph17103730

Shaw R, Kim YK, Hua J. Governance, technology and citizen behavior in pandemic: lessons from COVID-19 in East Asia. Progress in Disaster Science. 2020;6:100090. https://doi.org/10.1016/j.pdisas. 2020.100090

Simon N, et al. The role and response of palliative care and hospice services in epidemics and pandemics: a rapid review to inform practice during the COVID-19 pandemic. J Pain Symptom Manage. 2020. https://doi.org/10.1016/j.jpainsymman.2020.03.029. 
Singh, et al. Internet of things (IoT) applications to fight against COVID-19 pandemic. Diabetes Metab Syndr. 2020;14(4):521-4. https://doi.org/10.1016/j.dsx.2020.04.041.

Smith WR, Atala AJ, Terlecki RP, Kelly EE, Matthews CA. Implementation guide for rapid integration of an outpatient telemedicine program during the COVID-19 pandemic. J Am Coll Surg. 2020. https://doi.org/10.1016/j.jamcollsurg.2020.04.030.

Sun Niuniu, et al. A qualitative study on the psychological experience of caregivers of COVID-19 patients. Am J Infect Control. 2020. https://doi.org/10.1016/j.ajic.2020.03.018.

Takhar A, Walker A, Tricklebank S, Wyncoll D, Hart N, Jacob T, Arora A, Skilbeck C, Simo R, Surda P. Recommendation of a practical guideline for safe tracheostomy during the COVID-19 pandemic. Eur Arch Otorhinolaryngol. 2020;277(8):2173-84. https://doi.org/ 10.1007/s00405-020-05993-x.

Tandon V, Raheja A, Mishra S, Garg K, Dash C, Borkar SA, Wellington J, Chaurasia B, Fontanella MM, Suri A, Chandra PS. Trends in neurosurgical teleconsultation services across the globe during COVID-19 pandemic. World Neurosurg. 2021. https://doi.org/10. 1016/j.wneu.2021.03.070.

Tempe DK, Khilnani GC, Passey JC, Sherwal BL. Challenges in preparing and managing the critical care services for a large urban area during COVID-19 outbreak: perspective from Delhi. J Cardiothorac Vasc Anesth. 2020. https://doi.org/10.1053/j.jvca.2020. 05.028 .

Tey J, Ho S, Choo BA, Ho F, Yap SP, Tuan JK, ... \& Wang ML. Navigating the challenges of the COVID-19 outbreak: perspectives from the radiation oncology service in Singapore. Radiotherapy and Oncology. 2020. https://doi.org/10.1016/j.radonc.2020.03.030

Ting DSW, Carin L, Dzau V, Wong TY. Digital technology and COVID-19. Nat Med. 2020;26:459-61. https://doi.org/10.1038/ s41591-020-0824-5.

Ucar F, Korkmaz D. COVIDiagnosis-Net: Deep Bayes-SqueezeNet based diagnostic of the coronavirus disease 2019 (COVID-19) from X-ray images. Med Hypotheses. 2020;140:109761. https:// doi.org/10.1016/j.mehy.2020.109761.

Vaishya R, Vaish A. Roles and responsibilities of the orthopaedic community and the society during COVID-19 pandemic. Indian J Orthop. 2020;54(3):398-9. https://doi.org/10.1007/ s43465-020-00105-7.

Vaishya R, Haleem A, Vaish A, Javaid M. Emerging technologies to combat the COVID-19 pandemic. J Clin Exp Hepatol. 2020;10(4):409-11. https://doi.org/10.1016/j.jceh.2020.04.019.

Vaid S, Kalantar R, Bhandari M. Deep learning COVID-19 detection bias: accuracy through artificial intelligence. Int Orthop. 2020;44(8):1539-42. https://doi.org/10.1007/ s00264-020-04609-7.

World Health Organizations (2021), COVID-19 weekly epidemiological update, Available at https://www.who.int/publications/m/item/ weekly-epidemiological-update-on-covid-19---20-april-2021. Accessed on 21-04-2021.

Wang CJ, Ng CY, Brook RH. Response to COVID-19 in Taiwan: big data analytics, new technology, and proactive testing. JAMA. 2020. https://doi.org/10.1001/jama.2020.3151.

Yang Y, Zhou Y, Liu X, Tan J. Health services provision of 48 public tertiary dental hospitals during the COVID-19 epidemic in China. Clin Oral Investig. 2020;24(5):1861-4. https://doi.org/10.1007/ s00784-020-03267-8.

Zhou C, Su F, Pei T, Zhang A, Du Y, Luo B, ... \& Song C. COVID-19: challenges to GIS with big data. Geography and Sustainability. 2020. https://doi.org/10.1007/s00264-020-04609-7.

Publisher's note Springer Nature remains neutral with regard to jurisdictional claims in published maps and institutional affiliations. 